\title{
Lateral Buckling Analysis of the Steel-Concrete Composite Beams in Negative Moment Region
}

\author{
Fengqi Guo, Shun Zhou, and Lizhong Jiang \\ School of Civil Engineering, Central South University, Changsha 410075, China \\ Correspondence should be addressed to Fengqi Guo; fengqiguo@csu.edu.cn
}

Received 30 April 2015; Revised 7 July 2015; Accepted 7 July 2015

Academic Editor: João M. P. Q. Delgado

Copyright ( 2015 Fengqi Guo et al. This is an open access article distributed under the Creative Commons Attribution License, which permits unrestricted use, distribution, and reproduction in any medium, provided the original work is properly cited.

\begin{abstract}
Distortional buckling is one of the important buckling models of steel-concrete composite beam in negative moment region. Rotation restraining rigidity and lateral restraining rigidity which steel beam web to bottom plate of steel-concrete composite are the key factors to influence the distortional buckling behavior. A comprehensive and intensive study on rotation restraining rigidity and lateral restraining rigidity which steel beam web to bottom plate of I-shaped steel-concrete composite beam in negative moment region is conducted in this paper. Energy variation principle is adopted to deduce the analytical expressions to calculate the rotation restraining rigidity and lateral restraining rigidity. Combined with the buckling theory of axial compression thin-walled bars in elastic medium, the buckling moment is obtained. Theoretical analysis shows that the rotation restraining rigidity and lateral restraining rigidity of steel beam web appear to have a linear relationship with the external loads and could also be negative. Compared with other methods, the results calculated by the proposed expressions agree well with the numerical results by ANSYS. The proposed expressions are more concise and suitable than the existing formulas for the engineering application.
\end{abstract}

\section{Introduction}

The steel-concrete composite beam is composed of profiled steel or welded I-shaped beam and concrete slab through shear connectors, which can resist external loads together. Because this composite structure combines the tensile resistance of steel with the compressive resistance of concrete, it has the advantages of higher bearing capacity, better plasticity and ductility, constructing conveniently, and lower cost, which makes it widely used in long-span bridges and highrise buildings. In practical engineering, it is unnecessary to verify the lateral buckling of composite beams in positive bending moment region because of the enough bending rigidity and torsional rigidity of concrete slab. However, with bigger variable loads and unfavorable loads, the bottom flange of steel beam in the negative moment region would yield lateral buckling associated with web transverse deformation. The distortion buckling is then likely to occur.

In recent years, several scholars used the energy variational methods to analyze global stability of composite beam. Some authors computed the critical buckling load [1-3] and others compiled the corresponding specifications [4]. These specifications only consider global bending instability of the steel beam web but fail to take into account the distortional buckling. Besides, the critical load formulas by these methods are a little tedious for engineering calculations. Based on the elastic foundation compressive bar method, Williams and Jemah [5], Svensson [6], Goltermann and Svensson [7], and Ronagh [8] successively study the stability of composite beam under constant axial force, increasing the contribution of torsional rigidity of the concrete slabs and participating area of the steel girder web plate. In order to consider the effect of bending moment gradient compressive bar variable, the axial force is introduced. Diansheng and Xiaomin [9] presented a model for analyzing the local buckling property of cold-formed thin-wall steel-concrete composite beam. The elastic buckling stresses at steel beam web and flange wall are calculated by the energy method. Jiang $[10,11]$ researched the local stability in the negative moment region for steel beam web of continuous composite beams in attempt to establish the simplified calculation model of local stability under various loads and propose the critical local buckling 


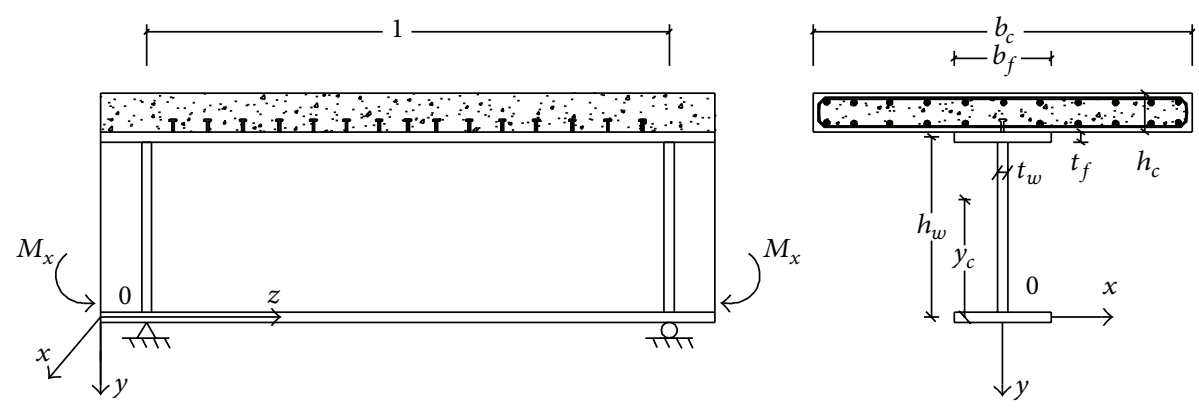

FIGURE 1: Cross section dimensions of steel-concrete composite beams and axes.

stress formula under a variety of stress states. Ye and Chen [12] improved Svensson compressive bar model appropriately. Considering the steel beam web effective participation part, two variable axial forces distortional buckling stability critical load calculation formulas were deduced based on the improved model. Making use of the finite element, the accuracy of the above method was analyzed by calculating the composite beam constraint distortional buckling load. Zhou et al. $[13,14]$ used energy variation principle to deduce the calculation method of rotation restraining rigidity and lateral restraining rigidity.

In this paper, a comprehensive and intensive study on rotation restraining rigidity and lateral restraining rigidity which steel beam web to bottom plate of steel-concrete composite beam in negative moment region is conducted. The energy method is used to deduce the theoretical formula for rotation restraining rigidity and lateral restraining rigidity which the steel beam web provides for bottom plate. Energy variation principle is adopted to derive the steel beam critical stress of positive symmetry bending buckling and dissymmetry bending-torsion buckling in order to calculate the buckling moment. In the end of the paper, the proposed formulas are discussed and analyzed.

\section{Basic Assumptions}

The schematic diagram of steel-concrete composite beam is shown in Figure 1. The lateral buckling model of steel Ishaped beam in composite beam is different from the free simply supported steel beam (unconstrained steel beam). The top flange of steel beam constituted by concrete slab has big stiffness, so the lateral deformation and torsional deformation are restricted to a certain degree. The bottom flange of steel beam is under compression. Although it can yield lateral displacement and torsion angle, the bottom flange constrained by the web is not perfectly free. Therefore, the lateral buckling of composite beam can be regarded as the distortional buckling in company with lateral bending deformation of steel beam web.

The right handed coordinate system $x y z$ is fixed to the centroid of steel beam bottom flange. As shown in Figure 1, the monosymmetrical composite beam bears a bending moment $M_{x}$ in the $y z$ plane which shows big stiffness. In order to analyze the rotation restraining rigidity $k_{\varphi}$ of steel

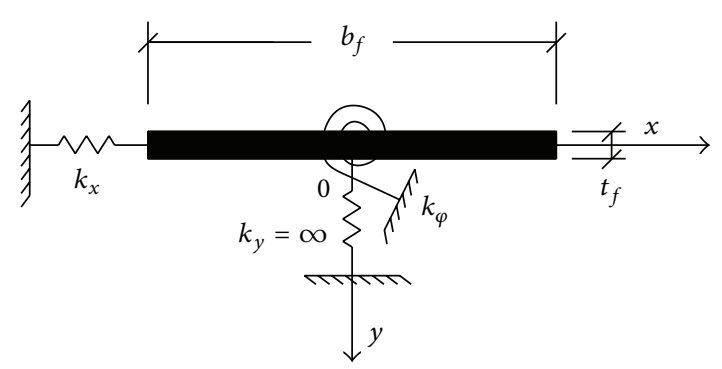

FIgURE 2: Simplified calculation model of steel-concrete composite beams.

beam bottom flange to web and the buckling moment, some assumptions are made as follows:

(1) The materials are isotropic and perfectly elastic body.

(2) The element is constant section beam and there were no initial imperfections.

(3) The cross-sectional shape of steel beam bottom flange does not change during distortional buckling yielding.

(4) The lateral deformation and torsional deformation of steel beam top flange could not happen because of enough stiffness of concrete slab.

(5) Due to the negative moment, most of concrete in composite beam has been cracked when buckling yields. Therefore, the bending capacity of concrete is ignored, which means that only the bending capacity of the steel reinforcements in concrete slab is considered.

(6) The vertical restraining rigidity which webs to bottom flange $k_{y}=\infty$.

Based on above assumptions, the problem to be analyzed can be simplified as a thin-walled constraint distortion problem which is restricted by spring restraint and vertical rigid constraint in horizontal and distortion direction. The simplified model is plotted in Figure 2.

\section{Web Constraint Factor $k_{\phi}$ and $k_{x}$}

3.1. Rotation Constraint Rigidity $k_{\phi}$. Figure 3 presents a halfwave length of web section under consideration. The width 


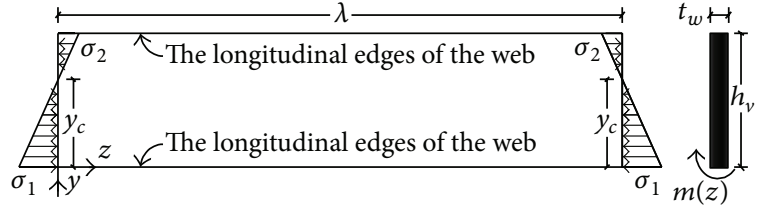

FIGURE 3: Rectangular plate subjected to compression and moments.

and thickness of web section are $h_{w}$ and $t_{w}$, respectively. $\lambda$ refers to the half-wave length of web caused by distortion buckling in longitudinal direction (called as the half-wave length hereafter). Two transversal opposite sides are simply supported. The side connected to top flange is fixed and the other side connected to bottom flange is simply supported. The two simply supported sides bear the longitudinal linear distributed stress $\sigma$ in $Z$ direction (compressive stress is positive and tension stress is negative). The side connected to bottom flange bears the equivalent spring constraint moment $m(z)$ which bottom flange exerted on web. The coordinate of gravity centre of steel beam total cross section is represented by $-y_{c}$, and the moment of inertia is $I$. According to the assumptions mentioned above, when the negative moment $M_{x}$ acts on the reinforcement in concrete slab, the axial compressive stress at bottom edge of web is $\sigma_{1}=M_{x} y_{c} / I$ and the axial compressive stress at top edge of web is $\sigma_{2}=$ $\sigma_{1}\left(y_{c}-h_{w}\right) / y_{c}$. Therefore, the axial compressive stress at other points of web is $\sigma=\sigma_{1}\left(y_{c}+y\right) / y_{c}$.

Assuming $D=E t_{w}^{3} / 12\left(1-\mu^{2}\right), \mu$ is Poisson's ratio of steel; $E$ is the elastic modulus of steel; $u$ denotes the deformation function of web. The boundary conditions of $u$ can be expressed as

$$
\begin{aligned}
{[u]_{z=0, \lambda} } & =0, \\
{[u]_{y=0,-h_{w}} } & =0, \\
{\left[\frac{\partial u}{\partial y}\right]_{y=-h_{w}} } & =0, \\
{\left[-D\left(\frac{\partial^{2} u}{\partial z^{2}}+\mu \frac{\partial^{2} u}{\partial y^{2}}\right)\right]_{z=0, \lambda} } & =0 .
\end{aligned}
$$

With (1), the displacement functions are written as

$$
u=c\left[\frac{y}{h_{w}}+2\left(\frac{y}{h_{w}}\right)^{2}+\left(\frac{y}{h_{w}}\right)^{3}\right] \sin \frac{\pi z}{\lambda}
$$

The strain energy of half-wave length web in the case of small deformations is [16-18]

$$
\begin{aligned}
U_{1} & =\frac{D}{2} \int_{0}^{\lambda} \int_{-h_{w}}^{0}\left[\left(\frac{\partial^{2} u}{\partial y^{2}}\right)^{2}+\left(\frac{\partial^{2} u}{\partial z^{2}}\right)^{2}+2 \mu \frac{\partial^{2} u}{\partial y^{2}} \frac{\partial^{2} u}{\partial z^{2}}\right. \\
& \left.+2(1-\mu)\left(\frac{\partial^{2} u}{\partial y \partial z}\right)^{2}\right] d y d z .
\end{aligned}
$$

Substituting (2) into (3) leads to the fact that

$$
U_{1}=\frac{\lambda D}{2}\left[\frac{2 c^{2}}{h_{w}^{3}}+\frac{2 c^{2}}{15 h_{w}}\left(\frac{\pi}{\lambda}\right)^{2}+\frac{c^{2} h_{w}}{210}\left(\frac{\pi}{\lambda}\right)^{4}\right] .
$$

The elastic potential energy caused by half-wave length longitudinal side spring constraint is

$$
U_{2}=\frac{k_{\varphi}}{2} \int_{0}^{\lambda}\left(\frac{\partial u}{\partial y}\right)_{y=0}^{2} d z
$$

Substituting (2) into (5),

$$
U_{2}=\frac{\lambda k_{\varphi} c^{2}}{4 h_{w}{ }^{2}} .
$$

The external force work of half-wave length web can be computed by [16-18]

$$
\begin{aligned}
W & =\frac{t_{w}}{2} \int_{0}^{\lambda} \int_{-h_{w}}^{0} \sigma\left(\frac{\partial u}{\partial z}\right)^{2} d y d z \\
& =\frac{t_{w}}{2} \int_{0}^{\lambda} \int_{-h_{w}}^{0} \frac{\sigma_{1}\left(y_{c}+y\right)}{y_{c}}\left(\frac{\partial u}{\partial z}\right)^{2} d y d z .
\end{aligned}
$$

Substituting (5) into (8),

$$
W=\frac{\lambda c^{2} \sigma_{1} t_{w} h_{w}}{420}\left(\frac{\pi}{\lambda}\right)^{2}-\frac{\lambda c^{2} \sigma_{1} t_{w} h_{w}^{2}}{1120 y_{c}}\left(\frac{\pi}{\lambda}\right)^{2} .
$$

The total potential energy of half-wave length web is

$$
\Pi=U_{1}+U_{2}-W .
$$

Substitution of (4), (6), and (8) into (9) results in

$$
\begin{aligned}
\Pi= & \frac{\lambda D}{2}\left[\frac{2 c^{2}}{h_{w}^{3}}+\frac{2 c^{2}}{15 h_{w}}\left(\frac{\pi}{\lambda}\right)^{2}+\frac{c^{2} h_{w}}{210}\left(\frac{\pi}{\lambda}\right)^{4}\right] \\
& +\frac{\lambda k_{\varphi} c^{2}}{4 h_{w}^{2}}-\frac{\lambda c^{2} \sigma_{1} t_{w} h_{w}}{420}\left(\frac{\pi}{\lambda}\right)^{2} \\
& +\frac{\lambda c^{2} \sigma_{1} t_{w} h_{w}^{2}}{1120 y_{c}}\left(\frac{\pi}{\lambda}\right)^{2} .
\end{aligned}
$$

Based on principle of resident potential energy, we obtained the following:

$$
\begin{gathered}
\frac{D}{2}\left[\frac{2}{h_{w}^{3}}+\frac{2}{15 h_{w}}\left(\frac{\pi}{\lambda}\right)^{2}+\frac{h_{w}}{210}\left(\frac{\pi}{\lambda}\right)^{4}\right]+\frac{k_{\varphi}}{4 h_{w}^{2}} \\
-\frac{\sigma_{1} t_{w} h_{w}}{420}\left(\frac{\pi}{\lambda}\right)^{2}+\frac{\sigma_{1} t_{w} h_{w}^{2}}{1120 y_{c}}\left(\frac{\pi}{\lambda}\right)^{2}=0 .
\end{gathered}
$$

By solving (11), one can obtain

$$
\begin{aligned}
k_{\varphi}= & \left(\frac{t_{w} h_{w}^{3}}{105}-\frac{t_{w} h_{w}^{4}}{280 y_{c}}\right)\left(\frac{\pi}{\lambda}\right)^{2} \sigma_{1} \\
& -D\left[\frac{4}{h_{w}}+\frac{4 h_{w}}{15}\left(\frac{\pi}{\lambda}\right)^{2}+\frac{h_{w}^{3}}{105}\left(\frac{\pi}{\lambda}\right)^{4}\right] .
\end{aligned}
$$




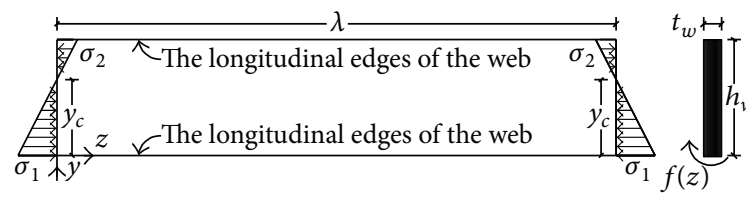

Figure 4: Rectangular plate subjected to compression and lateral stress.

3.2. Lateral Constraint Rigidity $k_{x}$. The half-wave length of web section is shown in Figure 4. Two transversal opposite sides are simply supported. The side connected to top flange is fixed and the other side connected to bottom flange can move laterally. The two simply supported sides bear the longitudinal linear distributed stress $\sigma$ in $Z$ direction (similarly, compressive stress is taken as positive and tension stress is negative). The side connected to bottom flange bears the equivalent spring constraint distributed force $f(z)$ which bottom flange exerted on web.

Based on above analysis, the boundary conditions of $u$ can be expressed as

$$
\begin{aligned}
{[u]_{z=0, \lambda} } & =0, \\
{[u]_{y=-h_{w}} } & =0, \\
{\left[\frac{\partial u}{\partial y}\right]_{y=0,-h_{w}} } & =0 \\
{\left[-D\left(\frac{\partial^{2} u}{\partial z^{2}}+\mu \frac{\partial^{2} u}{\partial y^{2}}\right)\right]_{z=0, \lambda} } & =0 .
\end{aligned}
$$

According to above boundary conditions, the displacement functions can be written as

$$
u=\left[c-3 c\left(\frac{y}{h_{w}}\right)^{2}-2 c\left(\frac{y}{h_{w}}\right)^{3}\right] \sin \frac{\pi z}{\lambda} .
$$

Substituting (14) into (3), the strain energy of half-wave length web in the case of small deformations is then obtained as follows:

$$
U_{1}=\frac{\lambda D}{2}\left[\frac{6 c^{2}}{h_{w}^{3}}+\frac{13 c^{2} h_{w}}{70}\left(\frac{\pi}{\lambda}\right)^{4}+\frac{6 c^{2}}{5 h_{w}}\left(\frac{\pi}{\lambda}\right)^{2}\right] .
$$

The elastic potential energy caused by half-wave length longitudinal side spring constraint is

$$
U_{2}=\frac{k_{x}}{2} \int_{0}^{\lambda}[u]_{y=0}^{2} d z .
$$

Substituting (14) into (16) leads to the fact that

$$
U_{2}=\frac{\lambda k_{x} c^{2}}{4} \text {. }
$$

Substituting (14) into (7), the external force work of halfwave length web can be obtained as follows:

$$
W=\frac{13 \lambda c^{2} \sigma_{1} t_{w} h_{w}}{140}\left(\frac{\pi}{\lambda}\right)^{2}-\frac{3 \lambda c^{2} \sigma_{1} t_{w} h_{w}^{2}}{140 y_{c}}\left(\frac{\pi}{\lambda}\right)^{2} .
$$

Substituting (15), (17), and (18) into (9), the total potential energy of half-wave length web is

$$
\begin{aligned}
\Pi= & \frac{\lambda D}{2}\left[\frac{6 c^{2}}{h_{w}^{3}}+\frac{13 c^{2} h_{w}}{70}\left(\frac{\pi}{\lambda}\right)^{4}+\frac{6 c^{2}}{5 h_{w}}\left(\frac{\pi}{\lambda}\right)^{2}\right] \\
& +\frac{\lambda k_{x} c^{2}}{4}-\frac{13 \lambda c^{2} \sigma_{1} t_{w} h_{w}}{140}\left(\frac{\pi}{\lambda}\right)^{2} \\
& +\frac{3 \lambda c^{2} \sigma_{1} t_{w} h_{w}^{2}}{140 y_{c}}\left(\frac{\pi}{\lambda}\right)^{2} .
\end{aligned}
$$
have

Based on principle of resident potential energy, one can

$$
\begin{aligned}
\frac{D}{2}\left[\frac{6}{h_{w}^{3}}+\frac{6}{5 h_{w}}\left(\frac{\pi}{\lambda}\right)^{2}+\frac{13 h_{w}}{70}\left(\frac{\pi}{\lambda}\right)^{4}\right]+\frac{k_{x}}{4} \\
-\frac{13 \sigma_{1} t_{w} h_{w}}{140}\left(\frac{\pi}{\lambda}\right)^{2}+\frac{3 \sigma_{1} t_{w} h_{w}^{2}}{140 y_{c}}\left(\frac{\pi}{\lambda}\right)^{2}=0 .
\end{aligned}
$$

By solving (20), we obtained the following:

$$
\begin{aligned}
k_{x}= & \left(\frac{13 t_{w} h_{w}}{35}-\frac{3 t_{w} h_{w}^{2}}{35 y_{c}}\right)\left(\frac{\pi}{\lambda}\right)^{2} \sigma_{1} \\
& -D\left[\frac{12}{h_{w}{ }^{3}}+\frac{12}{5 h_{w}}\left(\frac{\pi}{\lambda}\right)^{2}+\frac{13 h_{w}}{35}\left(\frac{\pi}{\lambda}\right)^{4}\right] .
\end{aligned}
$$

\subsection{Discussion about $k_{x}$ and $k_{\phi}$}

(1) Equations (12) and (21) indicated that both $k_{\phi}$ and $k_{x}$ show a linear relationship with the longitudinal compressive stress $\sigma_{1}$. Generally, $h_{w} / y_{c}$ is less than 2 , so the coefficient before $\sigma_{1}$ is positive for most situations. The bigger $\sigma_{1}$ is the higher $k_{\phi}$ and $k_{x}$ are. At the same time, it is of interest to note that both $k_{\phi}$ and $k_{x}$ which steel beam bottom flange to web are determined by the compressive stress $\sigma_{1}$ but not by composite beam section properties.

(2) Since the polynomials on right-hand side of (12) and (21) have negative terms, $k_{\phi}$ and and $k_{x}$ could be negative. This is not consistent with regular positive definite rigidity and rigidity matrix. If the rotation constraint rigidity and lateral constraint rigidity are negative, the rotation and lateral displacement of steel beam bottom flange will be restricted by web. Namely, the steel beam web will restrict bottom flange to buckle, but the steel beam bottom flange will induce the web to buckle. According to [16], the lateral constraint rigidity $k=E t_{w}^{3} /\left(4 h_{w}^{3}\right)$ is obtained by using strip method in the elastic constraint compression member buckling model. However, the restraint action of two adjacent strips is not considered in this method. Therefore, the lateral constraint rigidity which has nothing to do with external forces is always positive. But this does not agree with the actual situation. Furthermore, the neglected rotation constraint rigidity will lead to certain errors when calculating buckling load of composite beam. 
(3) The ratios of the first term, second term, and third term on the right side of (21) and (12) are:

$$
\begin{aligned}
& \frac{\left(13 \sigma t_{w} h_{w} / 35\right)(\pi / \lambda)^{2}}{\left(\sigma t_{w} h_{w}^{3} / 105\right)(\pi / \lambda)^{2}}=\frac{39}{h_{w}^{2}}, \\
& \frac{\left(3 \sigma_{1} t_{w} h_{w}^{2} / 35 y_{c}\right)(\pi / \lambda)^{2}}{\left(\sigma_{1} t_{w} h_{w}^{4} / 280 y_{c}\right)(\pi / \lambda)^{2}}=\frac{24}{h_{w}^{2}}, \\
& \frac{D\left[12 / h_{w}^{3}+\left(12 / 5 h_{w}\right)(\pi / \lambda)^{2}+\left(13 h_{w} / 35\right)(\pi / \lambda)^{4}\right]}{D\left[4 / h_{w}+\left(4 h_{w} / 15\right)(\pi / \lambda)^{2}+\left(h_{w}^{3} / 105\right)(\pi / \lambda)^{4}\right]} \\
& \quad \approx \frac{3}{h_{w}^{2}} .
\end{aligned}
$$

From (22), $h_{w}^{2} k_{x} / k_{\varphi}$ is not an infinitesimal value, so the lateral constraint rigidity of bottom flange to web cannot be disregarded. Namely, in the calculation, the equation $k_{x}=0$ is not available. Therefore the lateral constraint rigidity of bottom flange to web cannot be approximated by zero. This is different from [16] in which the lateral constraint rigidity which the cold-formed thin-walled lipped channel steel webs to the top and bottom flange is taken as zero.

\section{Theoretical Derivation of Critical Moment}

4.1. Derivation of Critical Moment. The lateral constraint rigidity and rotation constraint rigidity which steel beam web to bottom flange can be simplified, respectively, as

$$
\begin{aligned}
k_{x} & =\alpha_{1} \beta \sigma+D \alpha_{2}, \\
k_{\varphi} & =\alpha_{3} \beta \sigma+D \alpha_{4}, \\
\beta & =\left(\frac{\pi}{\lambda}\right)^{2}, \\
\alpha_{1} & =t_{w} h_{w}\left(\frac{0.086 h_{w}}{y_{c}}-0.37\right), \\
\alpha_{2} & =\frac{12}{h_{w}^{3}}+\frac{2.4 \beta}{h_{w}}+0.37 h_{w} \beta^{2}, \\
\alpha_{3} & =t_{w} h_{w}^{3}\left(\frac{0.0036 h_{w}}{y_{c}}-0.0095\right), \\
\alpha_{4} & =\frac{4}{h_{w}}+0.27 h_{w} \beta+0.0095 h_{w}^{3} \beta^{2}, \\
\sigma & =\frac{M_{x} y_{c}}{I}=\frac{P}{A_{f}} .
\end{aligned}
$$

Therein, $D=E t_{w}^{3} /\left[12\left(1-\mu^{2}\right)\right] ; \mu$ is Poisson's ratio of steel; $\sigma$ represents the compressive stress of bottom flange; $P$ refers to the compressive force of bottom flange; $-y_{c}$ is the gravity centre coordinate of steel beam total cross section; $I$ is the inertia moment of steel beam; $\lambda=l / n$; $n$ is the buckling halfwave number; $A_{f}$ is the area of bottom flange.
As shown in Figure 2, the thin-walled member is doubly symmetric along $x$-axis and $y$-axis and the centre of origin $O$ coincides with the flexural center. The displacements of origin $O$ in $x$ direction and $y$ direction are denoted as $u$ and $v$, respectively. Because the rigidity in $y$ direction is infinity, $v$ is equal to zero. The equivalent distributed forces caused by elastic medium as a result of displacements of thin-walled member can be written as

$$
\begin{aligned}
& r_{x}=k_{x} u, \\
& r_{y}=k_{y} v,
\end{aligned}
$$

where $k_{x}$ and $k_{y}$ are the lateral and vertical constraint rigidity which web to bottom flange, respectively.

The torsional angle which the member rotates around the bending center is assumed to be $\varphi$. The equivalent distributed moment of torsional thin-walled member induced by equivalent spring is

$$
m=k_{\varphi} \varphi .
$$

Neutral balance differential equation of thin-walled member can be expressed as $[13,14]$

$$
\begin{aligned}
& E I_{y} u^{I V}+P\left(u^{\prime \prime}+y_{a} \varphi^{\prime \prime}\right)+k_{x}\left[u-\left(y_{d}-y_{a}\right) \varphi\right]=0, \\
& E I_{x} v^{I V}+P\left(v^{\prime \prime}-x_{a} \varphi^{\prime \prime}\right)+k_{y}\left[v+\left(x_{d}-x_{a}\right) \varphi\right]=0, \\
& E I_{w} \varphi^{I V}+\left(r_{0}^{2} P-G J\right) \varphi^{\prime \prime}-P\left(x_{a} v^{\prime \prime}-y_{a} u^{\prime \prime}\right) \\
& \quad-k_{x}\left[u-\left(y_{d}-y_{a}\right) \varphi\right]\left(y_{d}-y_{a}\right) \\
& \quad+k_{y}\left[v+\left(x_{d}-x_{a}\right) \varphi\right]\left(x_{d}-x_{a}\right)+k_{\varphi} \varphi=0 .
\end{aligned}
$$

Therein, $I_{y}=t_{f} b_{f}^{3} / 12 ; I_{x}=b_{f} t_{f}^{3} / 12 ; J=b_{f} t_{f}^{3} / 3 ; r_{0}^{2}=$ $x_{a}^{2}+y_{a}^{2}+\left(I_{x}+I_{y}\right) / A_{s}, A_{s}$ being the area of steel beam; $x_{a}$ is the horizontal coordinate of the bottom flange section bending centre, $x_{a}=0 ; y_{a}$ is the vertical coordinate of the bottom flange section bending centre, $y_{a}=0 ; x_{d}$ is the horizontal coordinate of the bottom flange section rotation axis, $x_{d}=$ $0 ; y_{d}$ is the vertical coordinate of the bottom flange section rotation axis, $y_{d}=0 ; I_{w}$ is the fan-shaped inertia moment of bottom flange section, $I_{w}=0$; $E$ is the tensile elastic modulus of steel; $G$ is the shear elastic modulus of steel.

With substitution of $y_{a}=0, y_{d}=0, x_{a}=0, v=0, I_{w}=0$, $k_{x}=0, x_{a}=0, y_{a}=0$, and $y_{d}=0$ into (30), one can obtain

$$
\begin{aligned}
E I_{y} I u^{I V}+y_{c} A_{f} M_{x} u^{\prime \prime}+\left(\alpha_{1} \beta y_{c} M_{x}+I D \alpha_{2}\right) u & =0, \\
k_{y}\left[v+\left(x_{d}-x_{a}\right) \varphi\right] & =0, \\
\left(r_{0}^{2} y_{c} A_{f} M_{x}-G J I\right) \varphi^{\prime \prime}+\left(\alpha_{3} \beta y_{c} M_{x}+I D \alpha_{4}\right) \varphi & =0 .
\end{aligned}
$$

When the steel-concrete composite beam in negative moment region bears lateral bending buckling, its neutral balance equation is shown in (31) and the corresponding boundary conditions are

$$
\begin{aligned}
{[u]_{z=0, l} } & =0, \\
{\left[u^{\prime \prime}\right]_{z=0, l} } & =0 .
\end{aligned}
$$


Assuming $u=A \sin (\sqrt{\beta} z)$, which satisfies the boundary conditions, according to Galerkin's method,

$$
\beta^{2}-\frac{M_{x} y_{c} A_{f}}{E I_{y} I} \beta+\frac{\left(\alpha_{1} \beta M_{x} y_{c} / I+D \alpha_{2}\right)}{E I_{y}}=0 .
$$

By solving (35),

$$
M_{c r 1}=\frac{E I_{y} \beta+D \alpha_{2} / \beta}{\left(A_{f}-\alpha_{1}\right) y_{c}} I .
$$

Due to $d M_{c r 1} / d \beta=0$, we obtained the following:

$$
\begin{aligned}
& \beta_{c r 1}=\frac{3.46}{\sqrt{E I_{y} h_{w}^{3} / D+0.37 h_{w}^{4}}}, \\
& n_{c r 1}=\frac{l \sqrt{\beta_{c r 1}}}{\pi} .
\end{aligned}
$$

If $l \sqrt{\beta_{c r 1}} / \pi$ is an integer, substitution of $\beta_{c r 1}$ into (36) leads to the lateral bending critical moment. If $l \sqrt{\beta_{c r 1}} / \pi$ is not an integer, the two values of $\beta_{c r 1}$ which makes $l \sqrt{\beta_{c r 1}} / \pi$ be two integers most near to $l \sqrt{\beta_{\text {cr } 1}} / \pi$ are then substituted into (36), and the smaller value is chosen to be the lateral bending critical moment.

When the steel beam bottom flange of steel-concrete composite beam in negative moment region suffers rotational buckling, the steel-concrete composite beam will yield lateral bending and torsional buckling. The neutral balance equation is seen in (33) and the boundary conditions are

$$
\begin{gathered}
{[\varphi]_{z=0, l}=0,} \\
{\left[\varphi^{\prime \prime}\right]_{z=0, l}=0 .}
\end{gathered}
$$

Assume $\xi^{2}=\left(\alpha_{3} \beta M_{x} y_{c} / I+D \alpha_{4}\right) /\left(r_{0}^{2} M_{x} y_{c} A_{f} / I-G J\right)$. Solving (33), we obtained the following:

$$
\varphi=A \sin \xi z+B \cos \xi z .
$$

Substituting (39) into (38) and with $\varphi \neq 0$, one can have

$$
\begin{aligned}
& \sin \xi l=0, \\
& \xi=\frac{n \pi}{l}=\sqrt{\beta}, \\
& \frac{\left(\alpha_{3} \beta M_{x} y_{c} / I+D \alpha_{4}\right)}{\left(r_{0}^{2} M_{x} y_{c} A_{f} / I-G J\right)}=\beta .
\end{aligned}
$$

Solving (42),

$$
M_{c r 2}=\frac{D \alpha_{4} / \beta+G J}{\left(r_{0}^{2} A_{f}-\alpha_{3}\right) y_{c}} I
$$

Because of the fact that $d M_{c r 2} / d \beta=0$, then

$$
\begin{aligned}
& \beta_{c r 2}=\frac{20.5}{h_{w}^{2}}, \\
& n_{c r 2}=\frac{l \sqrt{\beta_{c r 2}}}{\pi} .
\end{aligned}
$$

TABLE 1: Geometric dimension of examples.

\begin{tabular}{lcccc}
\hline Number of example & $h_{w} / \mathrm{mm}$ & $t_{w} / \mathrm{mm}$ & $t_{f} / \mathrm{mm}$ & $b_{f} / \mathrm{mm}$ \\
\hline 1 & 188.6 & 7 & 11.4 & 100 \\
2 & 188.6 & 7 & 10.4 & 100 \\
3 & 188.6 & 7 & 9.4 & 100 \\
4 & 188.6 & 8 & 9.4 & 100 \\
5 & 188.6 & 9 & 9.4 & 100 \\
6 & 150 & 8 & 9.4 & 100 \\
7 & 200 & 8 & 9.4 & 100 \\
8 & 200 & 8 & 9.4 & 80 \\
9 & 200 & 8 & 9.4 & 120 \\
\hline
\end{tabular}

When $l \sqrt{\beta_{c r 2}} / \pi$ is an integer, the substitution of $\beta_{c r 2}$ into (43) gets the lateral bending critical moment. When $l \sqrt{\beta_{c r 2}} / \pi$ is not an integer, a similar calculation mentioned before is taken to obtain the lateral bending critical moment.

After getting the lateral bending buckling critical moment $M_{c r 1}$ and the bending and torsional buckling critical moment $M_{c r 2}$ the smaller one of these two is taken as the buckling load of composite beam in negative moment region. The analytical results indicate that the composite beam in negative moment region yields as a result of lateral bending and torsional buckling acting together. Therefore, in $[11,12]$ the method in which only one case is considered is questionable. The presented work is an improvement to them.

To sum up, the calculation formula of buckling moment can be expressed as

$$
\begin{aligned}
& M_{c r} \\
& =\min \left\{\frac{E I_{y} \beta_{c r 1}+D \alpha_{2} / \beta_{c r 1}}{\left(A_{f}-\alpha_{1}\right) y_{c}} I, \frac{D \alpha_{4}}{\left(r_{0}^{2} A_{f}\right.},\right. \\
& \beta_{c r 1}=\frac{3.46}{\sqrt{E I_{y} h_{w}^{3} / D+0.37 h_{w}^{4}}}, \\
& \beta_{c r 2}=\frac{20.5}{h_{w}^{2}}, \\
& \alpha_{1}=t_{w} h_{w}\left(\frac{0.086 h_{w}}{y_{c}}-0.37\right), \\
& \alpha_{2}=\frac{12}{h_{w}^{3}}+\frac{2.4 \beta_{c r 1}}{h_{w}}+0.37 h_{w} \beta_{c r 1}^{2}, \\
& \alpha_{3}=t_{w} h_{w}^{3}\left(\frac{0.0036 h_{w}}{y_{c}}-0.0095\right), \\
& \alpha_{4}=\frac{4}{h_{w}}+0.27 h_{w} \beta_{c r 2}+0.0095 h_{w}^{3} \beta_{c r 2}^{2} .
\end{aligned}
$$$$
=\min \left\{\frac{E I_{y} \beta_{c r 1}+D \alpha_{2} / \beta_{c r 1}}{\left(A_{f}-\alpha_{1}\right) y_{c}} I, \frac{D \alpha_{4} / \beta_{c r 2}+G J}{\left(r_{0}^{2} A_{f}-\alpha_{3}\right) y_{c}} I\right\},
$$

When $l \sqrt{\beta_{c r 1}} / \pi$ is not an integer, substituting $\beta_{c r 1}$ that corresponds to two integers of the left and right side of $l \sqrt{\beta_{c r 1}} / \pi$ into (36), the smaller resulting value of $\beta_{c r 1}$ is the desired value. And when $l \sqrt{\beta_{c r 2}} / \pi$ is not an integer, substituting $\beta_{c r 2}$ that corresponds to two integers of the left 
TABLE 2: Calculation results.

\begin{tabular}{lcccc}
\hline Number of example & ANSYS/MPa & Literature method [4]/MPa & Literature method [15]/MPa & The proposed method/MPa \\
\hline 1 & $5.81 \times 10^{2}$ & $2.21 \times 10^{2}$ & $8.38 \times 10^{2}$ & $5.83 \times 10^{2}$ \\
2 & $5.46 \times 10^{2}$ & $2.05 \times 10^{2}$ & $8.32 \times 10^{2}$ & $5.51 \times 10^{2}$ \\
3 & $5.13 \times 10^{2}$ & $1.87 \times 10^{2}$ & $8.27 \times 10^{2}$ & $5.18 \times 10^{2}$ \\
4 & $6.13 \times 10^{2}$ & $2.13 \times 10^{2}$ & $12.2 \times 10^{2}$ & $6.28 \times 10^{2}$ \\
5 & $7.03 \times 10^{2}$ & $2.46 \times 10^{2}$ & $17.3 \times 10^{2}$ & $7.69 \times 10^{2}$ \\
6 & $6.32 \times 10^{2}$ & $2.56 \times 10^{2}$ & $19.2 \times 10^{2}$ & $6.29 \times 10^{2}$ \\
7 & $6.08 \times 10^{2}$ & $2.06 \times 10^{2}$ & $10.9 \times 10^{2}$ & $6.09 \times 10^{2}$ \\
8 & $4.80 \times 10^{2}$ & $1.38 \times 10^{2}$ & $10.8 \times 10^{2}$ & $4.89 \times 10^{2}$ \\
9 & $7.89 \times 10^{2}$ & $2.92 \times 10^{2}$ & $10.4 \times 10^{2}$ & $8.24 \times 10^{2}$ \\
\hline
\end{tabular}

and right side of $l \sqrt{\beta_{c r 2}} / \pi$ into (43), the smaller resulting value of $\beta_{c r 2}$ is the desired value.

4.2. Practical Example Analysis. Nine cases of I-shape steelconcrete composite beam are shown in Table 1. The length of specimen in negative moment region is equal to $4000 \mathrm{~mm}$. Finite element method is adopted to calculate these nine examples by using ANSYS, in which the concrete part of composite beam is substituted by lateral restraint and the steel I-beam is simulated by SHELL 43 . The method proposed by British Steel Construction Institution [4] and the buckling model method [15] are also used to calculate the buckling loads. The obtained results are shown in Table 2.

As shown in Table 2, the results obtained by buckling model method [15] tend to be excessively unsafe. The results by using the method proposed by British Steel Construction Institution [4] are too conservative. However, the results of the proposed method are in good agreement with those of ANSYS, which means that the proposed method is a reasonable and effective method.

\section{Conclusions}

Based on energy method, a comprehensive and intensive study on rotation restraining rigidity $k_{\phi}$ and lateral restraining rigidity $k_{x}$ which steel beam web to bottom plate of steel-concrete composite beam in negative moment region is performed in this paper. The expressions of lateral bending buckling stress, lateral bending, and torsional buckling stress and buckling moments of steel-concrete composite beam in negative moment region are deduced. Some conclusions are drawn as follows:

(1) Both the rotation constraint rigidity $k_{\phi}$ and the lateral constraint rigidity $k_{x}$ show a linear relationship with longitudinal compressive stress $\sigma_{1}$ at bottom flange.

(2) The rotation constraint rigidity $k_{\phi}$ and the lateral constraint rigidity $k_{x}$ could be negative. When the rotation constraint rigidity and the lateral constraint rigidity are negative that means the bottom flange of steel beam can be restrained by rotation or lateral constraint when steel beam was in negative moment region buckling.
(3) Since $h_{w}^{2} k_{x} / k_{\varphi}$ is not infinitesimal, the lateral constraint rigidity of bottom flange to web cannot be neglected. In other words, in the calculation, the equation $k_{x}=0$ cannot be used. Therefore it is proved theoretically that the lateral constraint rigidity of bottom flange to web cannot be approximated to be zero. This point is different with the steel structure.

(4) The results, obtained by literatures [4, 15] show some deviations with the ANSYS results. But the results by the presented expressions agree well with the ANSYS results. The reason is that the proposed expressions consider the lateral bending buckling and lateral bending-torsion buckling simultaneously. The proposed method is more reasonable and clearer in physical concepts in comparison with those methods which consider only one buckling mode. Besides, the proposed expressions are more concise and suitable for the engineering application.

\section{Conflict of Interests}

The authors declare that there is no conflict of interests regarding the publication of this paper.

\section{Acknowledgments}

The authors would like to acknowledge financial support from Projects (51078355) supported by National Natural Science Foundation of China, Projects (IRT1296) supported by the Program for Changjiang Scholars and Innovative Research Team in University (PCSIRT), and Project (12K104) supported by Scientific Research Fund of Hunan Provincial Education Department, China. Dr. Jing-Jing Qi and Dr. Wang-Bao Zhou have tried their best to help the authors. The authors express their sincere gratitude to Dr. Jing-Jing Qi and Dr. Wang-Bao Zhou.

\section{References}

[1] M. Ma and O. Hughes, "Lateral distortional buckling of monosymmetric I-beams under distributed vertical load," ThinWalled Structures, vol. 26, no. 2, pp. 123-143, 1996.

[2] M. A. Bradford, "Lateral-distortional buckling of continuously restrained columns," Journal of Constructional Steel Research, vol. 42, no. 2, pp. 121-139, 1997. 
[3] M. L.-H. Ng and H. R. Ronagh, "An analytical solution for the elastic lateral-distortional buckling of I-section beams," Advances in Structural Engineering, vol. 7, no. 2, pp. 189-200, 2004.

[4] R. M. Lawson and J. W. Raekham, Design of Haunched Composite Beams in Buildings, Steel Construction Institute, 1989.

[5] F. W. Williams and A. K. Jemah, "Buckling curves for elastically supported columns with varying axial force, to predict lateral buckling of beams," Journal of Constructional Steel Research, vol. 7, no. 2, pp. 133-147, 1987.

[6] S. E. Svensson, "Lateral buckling of beams analysed as elastically supported columns subject to a varying axial force," Journal of Constructional Steel Research, vol. 5, no. 3, pp. 179-193, 1985.

[7] P. Goltermann and S. E. Svensson, "Lateral distortional buckling: predicting elastic critical stress," Journal of Structural Engineering, vol. 114, no. 7, pp. 1606-1625, 1988.

[8] H. R. Ronagh, "Progress in the methods of analysis of restricted distortional buckling of composite bridge girders," Progress in Structural Engineering and Materials, vol. 3, no. 2, pp. 141-148, 2001.

[9] Z. Diansheng and Y. Xiaomin, "Study on beam local buckling of cold-formed thin-wall steel and concrete composite," Industrial Architecture, vol. 38, supplement, pp. 539-542, 2008.

[10] L.-Z. Jiang, L.-J. Zeng, and L.-L. Sun, "Steel-concrete composite continuous beam web local buckling analysis," Journal of Civil Engineering and Architecture, vol. 26, no. 3, pp. 27-31, 2009.

[11] L. Jiang and L. Sun, "The lateral buckling of steel-concrete composite box-beams," Journal of Huazhong University of Science and Technology (Urban Science Edition), vol. 25, no. 3, pp. 5-9, 2008.

[12] J. Ye and W. Chen, "Beam with elastic constraints of I-shaped steel-concrete composite distortional buckling," Journal of Building Structures, vol. 32, no. 6, pp. 82-91, 2011.

[13] W.-B. Zhou, L.-Z. Jiang, and Z.-W. Yu, "Analysis of beam negative moment zone of the elastic distortional buckling of steel-concrete composite," Journal of Central South University (Natural Science Edition), vol. 43, no. 6, pp. 2316-2323, 2012.

[14] W.-B. Zhou, L.-Z. Jiang, and Z.-W. Yu, “The calculation formula of steel concrete composite beams under negative bending zonedistortional buckling moment," Chinese Journal of Computational Mechanics, vol. 29, no. 3, pp. 446-451, 2012.

[15] P. Zhu, Steel-Concrete Composite Beam Design Theory, China Architecture \& Building Press, Beijing, China, 1989.

[16] J. Yao and J.-G. Teng, "Web rotational restraint in elastic distortional buckling of cold-formed lipped channel sections," Engineering Mechanics, vol. 25, no. 4, pp. 65-69, 2008.

[17] W.-B. Zhou, L.-Z. Jiang, and Z.-W. Yu, "Closed-form solution for shear lag effects of steel-concrete composite box beams considering shear deformation and slip," Journal of Central South University, vol. 19, no. 10, pp. 2976-2982, 2012.

[18] W.-B. Zhou, L.-Z. Jiang, and Z.-W. Yu, "Closed-form solution to thin-walled box girders considering the effects of shear deformation and shear lag," Journal of Central South University, vol. 19, no. 9, pp. 2650-2655, 2012. 

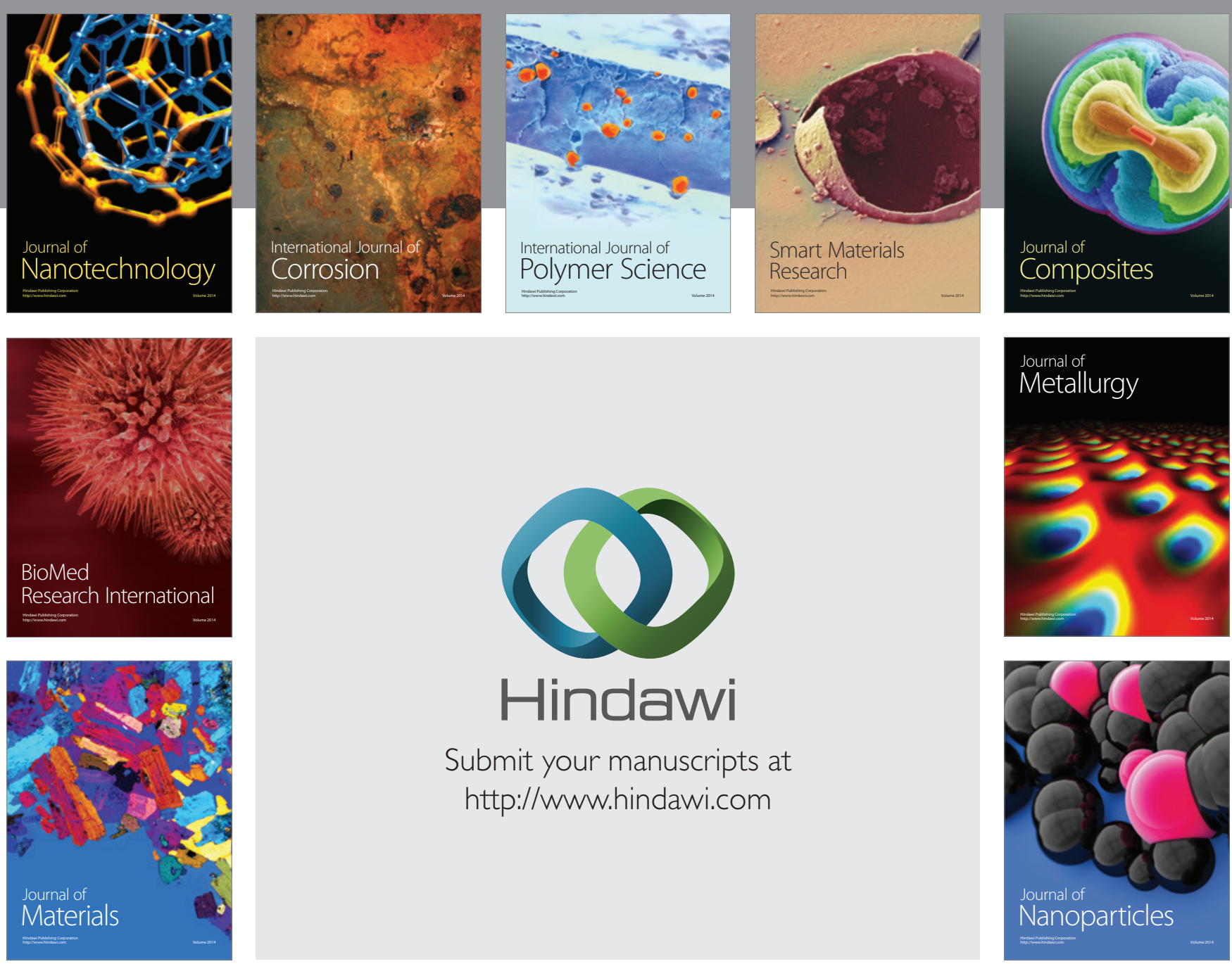

Submit your manuscripts at http://www.hindawi.com
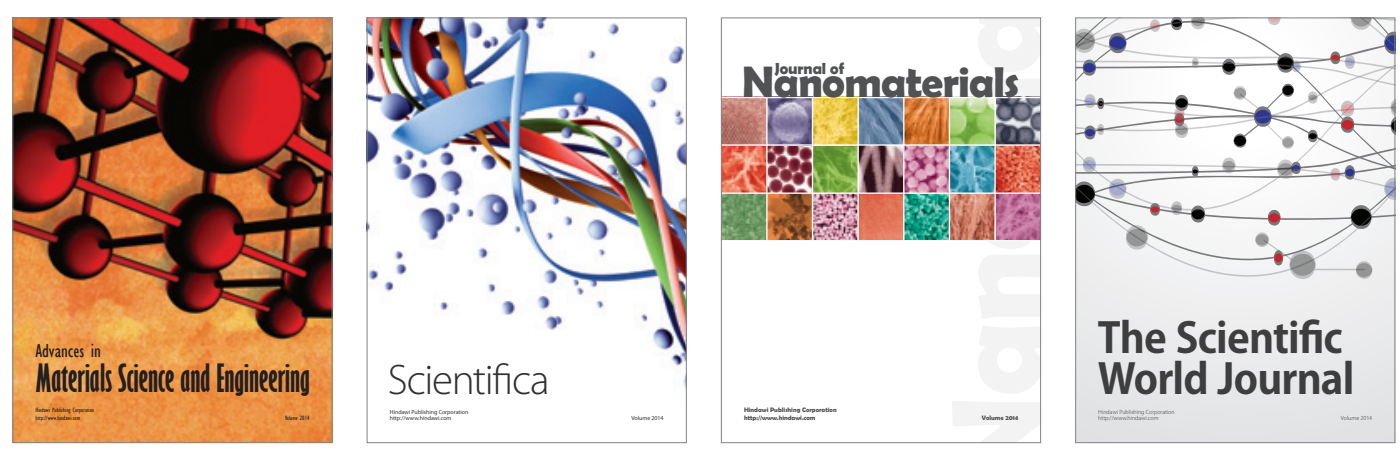

\section{The Scientific World Journal}
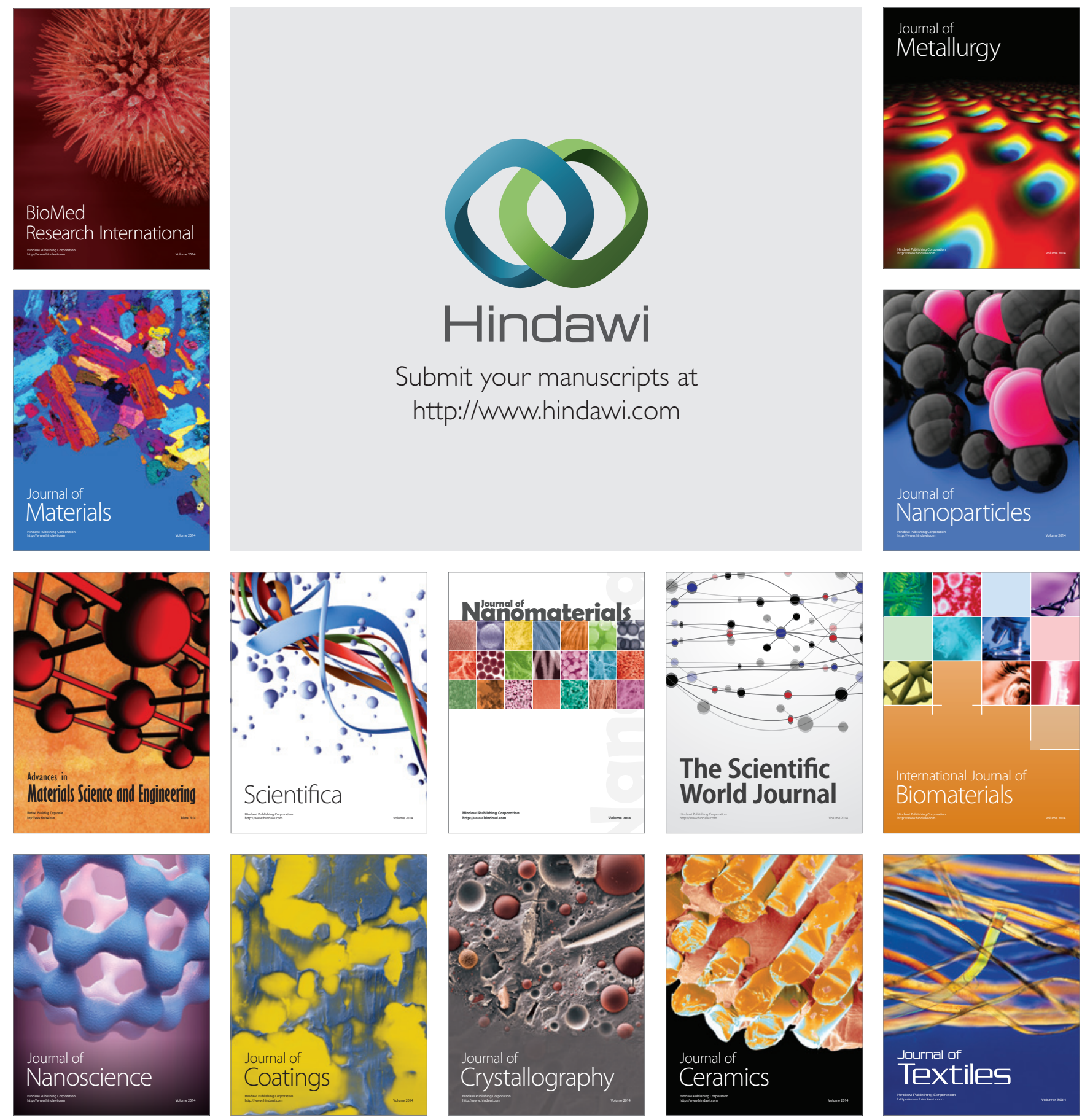